\title{
Pibid e as aprendizagens sobre a docência na relação universidade e escola
}

\author{
Elí Henn Fabris \\ Sandra de Oliveira \\ Universidade do Vale do Rio dos Sinos
}

\section{Resumo}

0 artigo apresenta resultados parciais de uma pesquisa financiada pelo CNPq. Nesse recorte analisamos as práticas pedagógicas e experiências vivenciadas no Programa Institucional de Bolsa de Iniciação à Docência (Pibid), buscando responder "o que aprendem sobre a docência esses atores institucionais?" e "em que lógica governamental estão ancoradas tais aprendizagens?" Como metodologia utilizamos a análise de questionários e blogs, orientada pelo referencial dos estudos foucaultianos e estudos sobre a docência. Resultados preliminares apontam para três grupos de enunciações que sinteticamente apresentamos através das seguintes expressões: Mobilização(1), Inovação(2), Parceria e trabalho coletivo(3).

Palavras-chave: Pibid. Formação inicial. Docência contemporânea. 


\section{Pibid and learning about the teaching profession in the relationship between university and school}

This paper introduces partial results of a research project funded by CNPq. We were interested in initial education processes in contemporary teaching production, and our investigative locus was the Programa Institucional de Bolsa de Iniciação à Docência (Pibid), where we sought to answer 'what do these institutional actors learn about teaching?', and 'on which governmental logics is this learning based?' As methodology we used the analysis of questionnaires and blogs, guided by reference to the studies of Foucault and studies on teaching. Preliminary results point to three groups of enunciations that are synthetically presented through the following expressions: Mobilization (1) Innovation (2), Partnership and collective work (3).

Keywords: Initiation to teaching. Initial teacher training. Contemporary teacher training.

\section{Pibid y el aprendizaje sobre la docencia en la relación universidad y escuela}

Este artículo presenta los resultados parciales de un estudio financiado por el CNPq. Este desglose analiza las prácticas de enseñanza y experiencias sobre el Programa Institucional de Beca de Iniciación a la Docencia (Pibid), buscando responder a las preguntas: “qqué aprenden sobre la docencia esos actores institucionales?" y “ien qué lógica gubernamental están basados tales aprendizajes?". Como metodología utilizar el análisis de los cuestionarios y blogs, guiado por referencia de los estudios de Foucault y os estudios sobre la enseñanza. Los resultados preliminares apuntan a tres grupos de enunciados que presentan sintéticamente a través de las siguientes expresiones: Movilización (1) Innovación (2), de Asociación y de Trabajo colectivo (3).

Palabras-clave: Iniciación a la docencia. Formación inicial. Docencia contemporánea. 


\section{Universidade e escola pública na iniciação à docência: a emergência do Pibid}

Nestes anos em que transitamos de aluno para professor é fundamental consolidar as bases de uma formação que tenha como referência lógicas de acompanhamento, de formação-em-situação, de análise da prática e de integração na cultura profissional docente. (Nóvoa, 2011, p. 45)

A formação de professores para a educação básica no Brasil passou por diversos impasses e, orientada por múltiplas políticas de formação, permanece com muitos desafios na contemporaneidade. 0 autor português, na epígrafe selecionada para dar início a esta seção, apresenta-nos uma reflexão importante para a área da formação de professores. Acreditamos que esse modo de entender a formação docente tem sua emergência neste tempo, criando as condições de possibilidade para que o Programa Institucional de Bolsa de Iniciação à Docência (Pibid) possa instalar-se de forma tão rápida e com resultados significativos em todo o país. Ele faz parte de uma lógica governamental que busca inserir cada ator envolvido em ações de parceria - ações em que todos se responsabilizam e todos buscam fazer até mesmo a parte que seria do Estado. Nesse sentido, o Estado parece mínimo, mas se fortalece em sua condição de governamentalidade. (Veiga-Neto, 2000)

Foucault (1997), em aula sobre o Nascimento da Biopolítica, chama a atenção para o fato de que no liberalismo "governa-se sempre demais", ou, como disse ele, "é preciso sempre suspeitar que se governa demais (p. 91)". Essa sensação de governamento intenso ocasiona certo incômodo que, após a ll Guerra Mundial, passa a ser questionado. Veiga-Neto (2000b) explica: "estava-se governando demais; e isso era visto como irracional porque antieconômico e retroalimentativo." (p. 194)

0 mesmo autor, ao falar sobre o desenvolvimento do liberalismo na segunda metade do século XX, diz que foi a partir das constatações sobre "governar demais" que surgiram duas tendências principais, uma alemã e outra norte-americana,

[...] são tais entendimentos do liberalismo que permitirão uma nova compreensão dos seus desenvolvimentos posteriores - aos quais se costuma denominar genericamente liberalismo avançado, tardio ou neoliberalismo. (Veiga-Neto, 2000b, p. 188)

Ao assumir o princípio da economia, o liberalismo torna-se mais sutil, apoiado na ideia de que "para governar mais, é preciso governar menos". Segundo VeigaNeto, o liberalismo ocupa-se do "governo da sociedade", a partir de uma sociedade formada "por sujeitos que são, cada um e ao mesmo tempo, objeto (governado de foral e parceiro (sujeito autogovernado) do governo. Em outras palavras, um sujeito com deveres e direitos, um sujeito-cidadão, um sujeito-parceiro". (2000b, p. 187)

O bem-estar, antes uma preocupação apenas do estado, cada vez mais, tem 
sido colocado como um dever da população. Na atualidade, a ideia de parceria estaria dentro dessa lógica: quanto mais parceiros, maior a economia, maior o lucro, melhor resultado; leia-se, custo-benefício. Ao apresentar o Pibid como uma possibilidade de desenvolvimento de uma política de formação alicerçada nas ideias da economia, salientamos que, como em qualquer proposta, é na sua ação, no seu desenvolvimento, que podemos perceber por onde transita, que discursos coloca em exercício e quais silencia ou deixa passar à margem.

Acreditamos que esse período de execução do programa já pode nos indicar algumas respostas para as perguntas que desejamos responder. No entanto, é importante ressaltar que nesse tipo de análise que desenvolvemos não há julgamento de valor, o que pretendemos é explicitar a produtividade de tal racionalidade e seus efeitos. Quando apresentamos os efeitos e produções de tal racionalidade não estamos afirmando que são efeitos positivos ou negativos, mas acreditamos que as análises desenvolvidas possam ser úteis na tomada de decisões na área da Educação, em especial, no campo da formação de professores.

O Pibid foi criado pela Coordenação de Aperfeiçoamento de Pessoal de Nível Superior (Capes)'1. A Capes, criada em 1951, foi instituída pelo poder público como Fundação Pública em 1992, sendo responsável pelo acompanhamento e avaliação dos cursos de pós-graduação strictu sensu brasileiros. Em 2007, a partir da Lei ${ }^{\circ}$ 11.502/2007, homologada pelo então presidente Luiz Inácio Lula da Silva, cria-se a chamada Nova Capes, que, além de coordenar o alto padrão do Sistema Nacional de Pós-Graduação, também passa a fomentar a formação inicial e continuada de professores para a educação básica. Tal atribuição é consolidada pelo Decreto $\mathrm{n}^{0}$ 6.755, de 29 de janeiro de 2009, que instituiu a Política Nacional de Formação de Profissionais do Magistério da Educação Básica. A partir dessa mudança em sua estrutura, a Capes passa a desenvolver diversas ações, de acordo com sua nova missão. É implementada uma série de programas que visam a contribuir para o aprimoramento da qualidade da educação básica e a estimular experiências inovadoras e o uso de recursos e tecnologias de comunicação e informação nas modalidades de educação presencial e a distância.

É nesse cenário e sob essas condições de possibilidade que o Pibid é criado. Entre os seus objetivos, estão: incentivar a carreira do magistério; garantir a qualidade da formação inicial de professores nos cursos de licenciatura; elevar o padrão de qualidade da educação básica para a melhoria do Índice de Desenvolvimento da Educação Básica (Ideb)².

Segundo o decreto ${ }^{3}$ que dispõe sobre o Pibid, "o programa visa proporcionar aos futuros professores a participação em experiências metodológicas, tecnológicas

1. Informações obtidas no site da Capes. Disponível em <http://www.capes.gov.br/>.

2. Índice de Desenvolvimento da Educação Básica - Ideb: avaliação criada para medir a qualidade de cada escola e de cada rede de ensino no Brasil. Disponível em <http://portal.mec.gov.br/>.

3. DECRETO n0 7.219, DE 24 DE JUNHO DE 2010. Dispõe sobre o Programa Institucional de Bolsa de Iniciação à Docência - Pibid e dá outras providências. Acesso em abril de 2011. Disponível em < http://www.jusbrasil.com. br/legislacao/823578/decreto-7219-10>. 
e práticas docentes de caráter inovador e interdisciplinar" (s/p). Conforme a proposta, a inserção dos licenciandos no cotidiano de escolas da rede pública promove a integração entre educação básica e educação superior. Outro objetivo do programa é tornar as escolas protagonistas nos processos formativos dos estudantes de licenciatura, mobilizando seus professores como coformadores dos futuros profissionais da educação.

0 primeiro edital, lançado em 2007, contemplava somente instituições federais. Em 2009, além das federais, puderam participar as instituições estaduais. Já em 2010, foram contempladas também as instituições municipais e comunitárias ${ }^{4}$, oportunidade em que o programa institucional, analisado nesta pesquisa, foi aprovado, sendo desenvolvido a partir de agosto de 2010.

0 respectivo projeto contempla cinco cursos de licenciatura: Física, Letras, Matemática, Pedagogia e Biologia. Nesse texto apresentamos análises da primeira etapa da pesquisa, quando se optou por analisar os processos de formação docente nesses cursos de licenciatura, tomando como superfície analítica os questionários respondidos por bolsistas e professores supervisores, bem como os blogs produzidos por esses sujeitos e demais envolvidos com o Pibid na instituição em que ocorre o projeto analisado.

\section{Sobre a grade de inteligibilidade}

Analisar a relação entre a escola e a universidade sob a ótica dos cenários e teorizações contemporâneas requer compreendê-la como produtora de cultura, de saberes, conhecimentos e práticas que produzem os sujeitos nela envolvidos em intensas e complexas redes de poder/saber/governo.

A aproximação com o campo em que os estudos foucaultianos se articulam com a educação tem possibilitado o exercício de pensar a escola, os processos de formação e a educação a partir de outro lugar. Os pensamentos de Foucault (1970) possibilitam-nos colocar sob suspeita alguns discursos que se constituíram como metanarrativas educacionais e a pensar outros modos de fazer educação. Para Veiga-Neto e Lopes (2010, p. 3), pensar de outro modo não significa

[...] ampliar o que já se pensa, ou seja, é mais do que acrescentar conteúdos novos ao que já se pensa e já se sabe. 0 'pensar de outro modo' se move a partir de uma atitude de suspeita frente a tudo aquilo que é dado e que parece óbvio e natural.

Interessadas em realizar uma análise do presente, valemo-nos de algumas possibilidades do pensamento foucaultiano para problematizar a formação inicial, investigando a constituição do sujeito professor para além do currículo dos

4. Universidades que não possuem fins lucrativos, consideradas instituições públicas não estatais. 
cursos. Para tanto, buscamos saber o que atores institucionais aprendem sobre a docência a partir das experiências vivenciadas na relação universidade e escola proporcionada pelo Pibid, na tentativa de compreender as práticas presentes na formação dos professores da educação básica brasileira e suas implicações no governo dos sujeitos. Práticas são tomadas como

[...] a racionalidade ou a regularidade que organiza o que os homens fazem (sistemas de ação na medida em que estão habitados pelo pensamento), que têm um caráter sistemático (saber, poder, ética) e geral (recorrente) e, por isso, constituem uma 'experiência' ou um 'pensamento'. (Castro, 2009, p. 338)

Sabendo, contudo, que cada prática está mergulhada numa atmosfera política e econômica, nosso objetivo foi olhar para as práticas para compreender como elas se constituem e suas implicações para o governamento da população e dos próprios sujeitos. Foucault será, pois, utilizado como uma forma operativa de trabalhar, e seus estudos serão tomados como uma grade de inteligibilidade.

O conceito operatório de governamentalidade que buscamos principalmente nos cursos do Collège de France de 1978 - Seguridade, Território e População - conforma a grade de inteligibilidade com a qual teceremos a problemática da pesquisa. Será nessa grade que buscaremos analisar tanto as aprendizagens sobre a docência desenvolvidas pelo Pibid, quanto a lógica governamental em que o programa está envolvido quando assume e desenvolve tais práticas de formação.

A noção de governamentalidade está ligada a formas de vida ou, ainda, a tecnologias de governamento que imprimem no sujeito algumas formas de vida. 0 sujeito é o ponto de articulação; podemos ler na sua experiência um conjunto de práticas que descrevem modos de vida de um tempo histórico ou podemos ver suas práticas como a materialidade ou a própria descrição de um tempo. É por isso que a noção de governamentalidade se revela importante para compreendermos o presente.

Foucault, através da análise de alguns dispositivos de segurança, buscou compreender historicamente o problema específico da população. Essa análise o levou à questão do governo. Em 1978, explicitou o seu desejo de fazer uma história da governamentalidade. Para Foucault, a governamentalidade não se revela na imposição de leis aos homens, mas na "esperteza" de utilizar-se das leis como tática para conduzir o comportamento dos homens. A esse conjunto de técnicas, processos, meios e instrumentos para condução do comportamento humano, Foucault chamou de "tecnologias de governo" ou, como traduz Veiga-Neto (2002), "tecnologias de governamento" 5 .

As tecnologias de governo interessam à educação e transformação dos

5. Sobre essa preferência de Veiga-Neto por traduzir governament como governamento e não como governo, buscar Veiga-Neto (2002). 
indivíduos, seja nas relações familiares, seja nas instituições. É por isso que Foucault estendeu a análise da governamentalidade dos outros para a análise do governo de si: "Eu chamo 'governamentalidade' o encontro entre as técnicas de dominação exercidas sobre os outros e as técnicas de si." (Foucault apud Revel, p. 55)

Para Bujes (2002, p. 82), falar em governamentalidade

[...] implica fazer uma análise das mentalidades, da razão e das práticas políticas que moldam o nosso presente"; é também "apontar como os dispositivos de subjetivação foram inventados e mostrar o impacto que têm as práticas de governamento sobre os sujeitos.

Podemos olhar para essas práticas como aquilo que Foucault chamou de "o governo pela verdade", uma prática de subjetivação, para o governo de si mesmo. Esse controle pós-moderno, segundo Veiga-Neto (2008, p.37), funciona para produzir corpos flexíveis, "é fácil entender o quanto isso tem a ver com a promoção das novas formas de assujeitamento e subjetivação no mundo atual".

As verdades instituem campos discursivos ou de "veridição" com efeito nas práticas de formação inicial de professores. Esses discursos são intensamente produtivos: ao produzir determinados sujeitos, colocam-nos em conformidade com uma racionalidade governamental. Desse modo, não criam somente novas práticas na formação inicial de professores para os anos iniciais da educação básica, mas produzem novos docentes - para esse nível de ensino - que estejam sintonizados com uma estratégia de regulação implicada num projeto político de desenvolvimento global.

Nos estudos que viemos realizando, a governamentalidade aparece como indissociável do processo de constituição do sujeito: ao mesmo tempo em que ela se revela como técnicas de dominação exercidas sobre os outros, ela é, também, técnica de si. Essas técnicas determinam o campo de ação dos sujeitos; regulam suas aspirações e desejos; instrumentalizam suas condutas em nome de um "novo cenário mundial", conduzindo-as para uma mesma direção. Assim, concordamos com Veiga-Neto, quando ele nos diz que "a governamentalidade é máxima, no neoliberalismo". (2008, p. 2003)

Inspiradas nas últimas publicações dos estudos de Foucault, "0 governo de si e dos outros" (2010) e "Do governo dos vivos" (2010), acerca da anarqueologia dos saberes, desejamos estar atentas às práticas que têm sido utilizadas para que os sujeitos se dobrem a determinadas verdades. Tentaremos identificar quais verdades têm constituído a formação inicial de professores nos cursos de licenciatura, em especial, os envolvidos no Pibid.

A operacionalização deu-se a partir de dois investimentos: o primeiro diz respeito ao que ganhou visibilidade nos blogs analisados. Importante ressaltar que os blogs do Pibid são utilizados como espaços de divulgação: das atividades 
desenvolvidas nos projetos e subprojetos das licenciaturas, dos avisos gerais, dos relatos dos bolsistas, de cursos, eventos e concursos de diferentes áreas e temáticas, das opiniões dos bolsistas sobre suas vivências nas escolas, filmagens em parceria com a TV da universidade e da interlocução com os diferentes sujeitos de alguma forma interpelados pelo programa. Ao olhar para os blogs, a ênfase desse estudo não esteve na ferramenta tecnológica analisada; importou pensar sobre o caráter produtivo dos blogs, não somente pelos discursos que fazem circular, mas também pelo campo de visibilidade e enunciação que criam.

0 segundo investimento diz respeito à realização dos questionários com 61 bolsistas das licenciaturas e com 17 professores supervisores das escolas participantes do projeto Pibid analisado. Posteriormente organizaram-se as respostas em quadros numerados, que receberam um título, conforme as recorrências identificadas.

Nos dois investimentos, respeitadas as diferenças dos materiais analisados, realizamos uma leitura, escrutinando dados e percepções de sentidos, buscando identificar as aprendizagens sobre docência que os atores envolvidos no Pibid vêm potencializando neste curto espaço de tempo. A análise procurou saber também como tais aprendizagens foram possíveis, emergindo nesse tempo.

Esses foram exercícios de muitas idas e vindas aos materiais, pois "verdades" não são visualizadas numa primeira leitura, mas vão ganhando sentido nas tramas formadas pelo entrecruzamento dos próprios materiais com os conceitos operadores. Elas não estão lá, prontas para serem encontradas, mas são resultado de um intenso investimento analítico. Ao manipular por diversas vezes os questionários e os materiais disponibilizados nos blogs, passamos a enxergar coisas que pareciam não estar lá à primeira vista. Conforme Foucault, "a verdade não existe fora do poder ou sem poder [...]. A verdade é deste mundo; ela é produzida nele graças a múltiplas coerções e nele produz efeitos regulamentados de poder." (Foucault, 2005, p. 12)

Os efeitos de que fala o filósofo e dos quais tratamos em nossas análises são os efeitos de poder próprios a um discurso considerado científico, legítimo, advindo de experts autorizados a falar sobre determinado assunto, nesse caso, especialmente o pedagógico. Porém, o que tentaremos deixar explícito é o quanto outros discursos de outras áreas, como a econômica, por exemplo, também se articulam para produzir as verdades e os sujeitos envolvidos na docência contemporânea.

Passadas as etapas de manuseio dos materiais, identificados os discursos recorrentes sobre as práticas que ganharam visibilidade no Pibid, organizamos essas recorrências em três grupos, apresentados neste artigo pelas unidades analíticas. Interessou-nos saber sobre as práticas colocadas em evidência, seja através dos questionários, seja através dos blogs, para poder pensar num tipo de docência (e de aprendizagens sobre a docência) que ali está se constituindo e, ainda, como essas verdades são construídas para fazer a condução do comportamento dos professores da educação básica na escola contemporânea. 
Passamos, então, a apresentar as análises realizadas até o presente momento e selecionadas para trabalhar neste texto, apontando para possíveis conexões da relação escola e universidade na produção da docência.

\section{As aprendizagens sobre a docência no Pibid}

Como explicitamos anteriormente, parte do material da pesquisa foi produzida a partir da aplicação de um questionário com 19 professores da escola da educação básica que atuam como supervisores do Pibid e com 61 alunos das licenciaturas que atuam como bolsistas de Iniciação à Docência em escolas. As perguntas tiveram como foco as experiências dos sujeitos envolvidos nos processos de Iniciação à Docência. Outra parte foi composta por materiais extraídos de nove blogs produzidos pelos diferentes sujeitos que fizeram parte do projeto Pibid analisado durante o ano de 2010 e 2011.

Após explorar a diversidade de informações, criamos arquivos para cada material analisado, separando as primeiras impressões acerca dos discursos que envolviam as aprendizagens sobre a docência. Realizamos uma leitura exaustiva e atenta desses materiais, escrutinando dados e percepções de sentidos, buscando identificar as regularidades enunciativas. Posteriormente fizemos o cruzamento dos achados dos questionários com os achados dos blogs, identificando os discursos recorrentes nos dois materiais e seus modos de funcionamento. Desse exercício resultou a organização dos três grupos de enunciações que, sistematizamos e identificamos como práticas que mobilizam as aprendizagens sobre a docência no Pibid.

\section{Grupo 1 - A mobilização das licenciaturas e das escolas: todos precisam participar}

Uma das regularidades enunciativas mais potentes que pudemos perceber nas respostas e nos relatos dos sujeitos envolvidos é a mobilização das licenciaturas e das escolas participantes para a discussão e problematização da formação docente na contemporaneidade.

Acreditamos que a parceria entre universidade e escola imprima no programa uma marca de partilha. Parece-nos muito significativa essa ideia de trabalho em parceria para a docência, o que já vem expresso nos próprios documentos do Pibid e se mostrou potente nos materiais analisados.

Ao olhar para os blogs produzidos pelos bolsistas e demais sujeitos envolvidos com o projeto Pibid analisado, pareceu-nos visível o desejo de transformar o grupo docente em força coletiva de criatividade, reflexão e ação, existindo um investimento 
na formação dos professores envolvidos num sentido amplo, contemplando não somente elementos específicos das áreas das licenciaturas envolvidas, mas também a formação ética, estética e política.

$\mathrm{Na}$ análise dos blogs do Pibid e dos demais materiais que o atravessam, percebemos que as ideias sobre colaboração permeiam grande parte das publicações e extrapolam o uso da ferramenta, evidenciando que a colaboração não está associada somente aos princípios do uso da própria ferramenta, mas que opera na produção das práticas desenvolvidas a partir do programa. Arriscamos dizer, a partir das enunciações encontradas nos blogs, que o Pibid opera na criação das possibilidades para a invenção de práticas pedagógicas que imprimam uma dimensão colaborativa. São práticas que colocam em operação mecanismos de subjetivação para a produção de uma docência específica a partir de

[...] arranjos entre práticas modernas e contemporâneas para a produção das subjetividades, cujos efeitos dependem dos sentidos dados e da operação de outros mecanismos operados em conjunto sobre os sujeitos. (Menezes, 2011, p. 41)

Foi possível perceber, por meio de fotos e filmagens postadas pelos bolsistas, a participação dos professores das escolas nas palestras, cursos e atividades propostas pelo programa. Observamos nos blogs um grande investimento no sentido da integração e articulação da universidade com a escola. Ficou claro que os bolsistas possuem a incumbência de movimentar não apenas as escolas, mas também as suas licenciaturas, motivando seus colegas a participar das atividades de formação desenvolvidas pelo Pibid.

Parece-nos que todos os subprojetos buscam deixar claro o quanto estão, de certa forma, movimentando as licenciaturas e as escolas, tornando as aulas mais interessantes e dinâmicas. 0 estímulo às perguntas, às experiências, à participação, à integração e às atividades práticas mostra o quanto os atores envolvidos buscam deslocar as práticas para uma ação constante e sistemática, desacomodando a escola, o que lemos como deslocamentos de práticas passivas para práticas ativas, de práticas localizadas na sala de aula para práticas desenvolvidas em outros espaços. Isso se confirma quando olhamos para os blogs e as respostas nos questionários. Abaixo apresentamos alguns excertos que selecionamos para que sirvam como exemplares do conjunto do material utilizado nas análises.

\section{Quadro 1: MOVIMENTANDO A ESCOLA}

\section{Post: Movimentando a escola}

0 PIBID-XXXXXX está em fase de muito trabalho nas escolas. Recebemos relatórios e registros de projetos e atividades que mostram o quanto supervisores, coordenadores, alunos e professores das escolas estão participando ativamente das ações. Este post mostra algumas dessas atividades.

Fonte: Banco de Dados da Pesquisa ${ }^{6}$, Blog Pibid, abril de 2011.

6. Todos os quadros presentes nesse artigo foram extraídos do banco de dados de pesquisa financiada pelo CNPq e desenvolvida em Programa de Pós-graduação em Educação. 


\section{Quadro 2: DESACOMODANDO A ESCOLA}

Percebemos diferenças em relação ao cuidado dos alunos com o ambiente escolar, com o pátio, com o lixo, que diminuiu consideravelmente nos últimos meses. Além de desacomodar professores, alunos, funcionários e direção da escola, o Pibid está movimentando a escola. É importante ressaltar, ainda, que o projeto, além de promover a integração entre Universidade e Escola, permite aos acadêmicos vivenciar os problemas enfrentados no dia a dia de uma escola pública, colaborando, dessa forma, para melhorar a qualidade da formação inicial de professores nos cursos de licenciaturas, onde sabemos que os estágios supervisionados e as práticas de ensino não têm dado conta dessas necessidades.

Fonte: Banco de Dados da Pesquisa, Supervisor 9, Ano 2011.

\section{Quadro 3: SAINDO DA SALA DE AULA}

Projeto Primavera, que ainda está sendo realizado na escola, em que os alunos do $2^{\circ}$ ano plantaram mudas de flores nos canteiros da escola, e assim, durante a semana, regam, recolocam adubo e estão sempre atentos aos acontecimentos no jardim da escola. Os alunos são superinteressados e participativos, o que nos motiva a atingir sucesso com o projeto.

Fonte: Banco de Dados da Pesquisa, Aluno 10, Ano 2011.

As experiências relatadas ou citadas pelos alunos das licenciaturas que participam do Pibid estão, em sua maioria, voltadas para propostas realizadas fora do espaço da sala de aula. Que docência produzem essas experiências de iniciação à docência no Pibid a partir do rompimento das fronteiras da sala de aula e até mesmo da escola?

Práticas ativas e interativas visibilizadas nos blogs anunciam na tessitura das redes o desejo de um trabalho pedagógico em consonância com o seu tempo. Podemos ler nesse movimento uma tentativa de deslocamento de práticas tidas como tradicionais, geralmente representadas pelas aulas expositivas, cópias do quadro, escritas no caderno, resolução de exercícios, ditados etc.

Conseguimos ler nesses textos práticas que conduzem a uma docência que rompe com a rotina escolar e, ousamos dizer, com os tempos e espaços escolares, buscando movimento. As propostas acontecem em salões, laboratórios, cinema, cemitério, e a sala de aula quase não aparece. Geralmente em formato de oficinas, as atividades propostas envolvem práticas que procuram romper com a passividade. Podemos dizer que são práticas ativas e que não ficam restritas à sala de aula. 0 espaço da sala de aula, por hora, praticamente não ganha visibilidade nos blogs e nem nos questionários analisados. A TV, o cinema, a poesia, a literatura, a música, o teatro são práticas selecionadas para contar o que fazem os alunos do Pibid como experiência de iniciação à docência, como podemos perceber nos excertos abaixo, extraídos dos blogs: 


\section{Quadro 4: AULAS DE CIÊNCIAS COM NOVA CARA}

A escola X é privilegiada. Para melhorar ainda mais o ensino, fez uma grande parceria com a Universidade A. As aulas de Ciências ganharam uma nova cara: alunos se empenham para, juntamente com os professores, deixar as aulas mais legais!

Fonte: Banco de Dados da Pesquisa, Blog Pibid, Março de 2011.

\section{Quadro 5: AULA MUITO LEGAL}

Aulas práticas com alunos de $6^{\circ}$ séries: observação de alguns animais invertebrados nas lupas. A atividade foi muito legal, e os alunos ficaram muito felizes por terem esta oportunidade, já que a escola ainda não possui laboratório.

Fonte: Banco de Dados da Pesquisa, Blog Pibid, Maio de 2011.

Por que essa necessidade de mobilização, referida pelos atores que atuam no Pibid? A mobilização anunciada é fruto desse conjunto de ações que movimentam tanto as licenciaturas quanto as escolas 0 que precisamos analisar é em que sentido essa mobilização se dá. Nos processos de regulação de um Estado governamentalizado, não é preciso que este assuma as ações diretamente, mas que produza seus efeitos pelas ações de cada sujeito que está envolvido em aprender a ser professor. 0 Pibid potencializa várias forças que serão produtivas nessa ação de chamar para a docência e ensinar sobre a docência a uma parcela da população que já não vem buscando a carreira há alguns anos, conforme mostram os estudos de Bernadete Gatti (2010)7 sobre as condições da profissão docente no Brasil e, especialmente, sobre a falta de atratividade da carreira docente no país. Se o Estado, por meio de ações da Capes, potencializa ações de mobilização, temos que entender que a governamentalidade produzida por tais processos é produtiva para que todos se articulem para os fins previstos. Vemos aqui em ação políticas públicas que fazem essa verdade ser potencializada - verdade que em si mesma não é positiva nem negativa, dependendo do que mobiliza e como mobiliza.

Isso nos possibilita inferir que uma análise crítica de tais processos sempre será necessária para que saibamos os significados atribuídos por cada universidade e cada área de conhecimento ao que seja mobilização das licenciaturas, das escolas e a desacomodação de todos. Mobilizar, movimentar, desacomodar pode funcionar como um potente chamamento do programa para ações mais desafiadoras, mas pode também ser tomado como um conjunto de práticas que se filiam ao imperativo de uma escola ativa e interativa, onde tudo que é passivo, silencioso, tradicional poderia ser lido como atrasado e fora do contexto de uma docência contemporânea.

7. GATTI, Bernadete et al. A atratividade da carreira docente no Brasil. In: Fundação Victor Civita (org.). Estudos e Pesquisas Educacionais (2007- 2009), São Paulo: FVC, n.1, mai. 2010. 


\section{Grupo 2 - Parceria e trabalho coletivo: todos são responsáveis}

As análises que compõem este texto correspondem a alguns olhares lançados sobre o material empírico da pesquisa já citada, considerando um problema pensado a partir da ótica da hipercrítica - "uma permanente reflexão e desconfiança radical frente a qualquer verdade dita ou estabelecida" (Veiga-Neto, 2003, p. 209) - e dos estudos das últimas produções da obra foucaultiana que têm chegado até nós - a anarqueologia dos saberes, que consiste no deslocamento analítico do eixo poder-saber para o eixo do "governo dos homens pela Verdade sob a forma da Subjetividade". (Foucault, 2010a)

Nesta etapa do exercício de análise, tratamos de encontrar e selecionar positividades dos discursos, na tentativa de mostrar os investimentos do Pibid sobre a formação de professores e a constituição de um tipo de docência ou, ainda, de tipos de aprendizagens sobre a docência. Emergiu do exercício analítico a discussão sobre a forma como a articulação entre a universidade e a escola tem operado não somente na formação inicial dos bolsistas, mas também na formação continuada dos professores das escolas participantes, inclusive movimentando os próprios cursos de licenciatura envolvidos, a partir da ideia de parceria e de trabalho coletivo para a responsabilização de todos. Observemos os excertos em destaque:

\section{Quadro 6: PARCERIA UNIVERSIDADE E ESCOLA}

Mesmo com muitos anos de magistério, foi um grande desafio assumir o cargo de supervisora do PIBID. Ter uma parceria com a universidade, (...) nos possibilitou inovação na elaboração dos planos de aula.

Fonte: Banco de Dados da Pesquisa, Supervisor 13, Ano 2011.

\section{Quadro 7: PARCERIA PROFESSOR E BOLSISTAS}

\section{Alunos do Ensino Fundamental, do Ensino Médio e do Curso Normal; professores, principalmente aqueles que estabelecem parceria com as bolsistas para acompanhamento de aulas ou desenvolvimento de projetos. Demais membros da comunidade escolar e os participantes do Pibid.}

Fonte: Banco de Dados da Pesquisa, Supervisor 2, Ano 2011.

Nas falas destacadas, podemos identificar que os efeitos da lógica da parceria estariam ligados ao compartilhamento de responsabilidade nessa governamentalidade neoliberal. Não podemos nos esquecer de que todas essas ações, observadas ou presentes nas falas dos sujeitos da pesquisa, estão articuladas a um programa que é promovido pelo Estado. Há um investimento nas ações, tanto das escolas quanto das universidades, para que a iniciação à docência aconteça. As 
ações do Pibid podem ser planejadas a partir de dados sobre a educação básica, com abrangência nacional, disponibilizados pelo IDEB. Muito mais econômico é controlar pela gestão do que participar de cada ação. Cabe ressaltar que não operamos com uma análise "negativa"; buscamos mostrar a produtividade dessas ações, pois entendemos a produtividade como algo que pode ser considerado negativo ou positivo ou, até mesmo, que potencializa produtividades complexas que não são fixas e nem totalmente iguais.

Talvez aqui esteja presente o reflexo da sociedade em que vivemos, focada no controle, e as movimentações que essas relações produzem no currículo e nos conhecimentos escolares. Parece-nos que programas como esse que analisamos estão articulados a essa lógica, muito mais de uma sociedade de controle do que de uma sociedade disciplinar, embora a regulação e o controle não se exerçam sem ações disciplinares.

Ainda podemos anunciar que todas essas aprendizagens sobre a docência parecem potencializar uma tecnologia de governamento, que é a participação. No primeiro grupo, vemos a mobilização da escola e das licenciaturas; no segundo grupo, aparece a parceria; no terceiro, como veremos logo adiante, é a vez da inovação como potência da universidade. Parece perpassar por esses grupos, colocando em ação suas propostas, uma tecnologia da participação. 0 que o Pibid da instituição analisada propõe é uma parceria com as escolas e com as universidades. Uma parceria que seja produtiva para conseguir evitar os riscos já destacados, como: não atratividade da carreira docente, a falta de professores e a ineficiência das licenciaturas, bem como das escolas de educação básica, com seus riscos potencializados na evasão e repetência. Talvez possamos anunciar que o programa funciona como um mobilizador para as práticas de governamento e regulação das escolas, para que, em conjunto com as universidades, invista ainda mais na prevenção dos riscos sociais. Nesse caso, parceria implica compartilhamento de responsabilidades: escolas e universidades parceiras na prevenção dos riscos sociais, tendo como órgão regulador/avaliador o Estado.

Podemos dizer que os investimentos nas parcerias estabelecidas pelo Pibid estão ligados à ideia de uma escola gerenciada. Nessa direção as escolas passam a ser gerenciadas como empresas a partir de uma lógica de mercado e, nesse empresariamento, a ênfase das práticas da escola voltam-se para a gestão. Seguindo essa linha de raciocínio, as ações do Pibid, ao resultarem em produção e em economia, fatores fundamentais para a lógica do mercado, têm se caracterizado como ações de inovação ou inovadoras. Mas que sentido a palavra inovação adquire no contexto do Pibid? Sobre esse último aspecto, vejamos a discussão a seguir: 


\title{
Grupo 3 - Inovação como potência na relação universidade e escola: 0 imperativo da inovação
}

\author{
Quadro 8: VETOR DE INOVAÇÃO
}

O Pibid leva um gás para a escola, eles (bolsistas) chegam cheios de energia e nos
desestabilizam, nos incomodam.

Fonte: Banco de Dados da Pesquisa, fala registrada em evento Pibid no ano de 2012.

Observamos, nas respostas dos questionários e nos materiais visibilizados nos blogs analisados, que os sujeitos participantes do Pibid, licenciandos e supervisores, no contexto do programa, associam inovação, principalmente, a novas teorias.

A universidade tem como tradição a pesquisa e uma forte representação na dimensão teórica de seu fazer. Com isso, há uma radical separação entre a escola e a universidade, como se a escola se detivesse na dimensão da prática e a universidade, na dimensão teórica, o que também aparece no quadro anteriormente apresentado. É forte a narrativa de que a diferença entre teoria e prática coloca a universidade em um polo e a escola em outro, como podemos observar no excerto que segue:

\section{Quadro 9: UNIVERSIDADE E ESCOLA}

Com certeza, como já disse, depois de ter saído há tanto tempo da universidade, as teorias ficam um pouco distantes. Apesar de estarmos em constantes pesquisas e formação dentro da escola, a Universidade sempre tem algo novo a acrescentar. Como exemplo, posso citar a construção do pôster relacionado, onde o embasamento teórico é bem importante.

Fonte: Banco de Dados da Pesquisa, Supervisor 3, Ano 2011.

Se, por um lado, fica reservado à universidade esse lugar da inovação, de novas teorias e de um distanciamento do "tradicional", é na escola que estaria todo o outro lado - o do atraso, do ultrapassado, do "tradicional" -, bem como o polo da prática. Assim, a potência da inovação estaria vinculada ao polo da universidade e, por isso, essa associação naturalizada de uma inovação pelas teorias fica restrita a esse espaço. Naturaliza-se essa posição e, desse modo, como ocorre com toda naturalização, outros processos que podem ocorrer ficam à margem ou nem são percebidos como possíveis. Se partirmos do pressuposto de que a universidade gera inovação e novas pesquisas e de que a escola é o lado do atraso e da estagnação, deixamos de perceber a vida que circula na escola e aceitamos a divisão teoria e prática, que tanto nos incomoda, dicotomizando os processos de criação e produção acadêmica e escolar. Se a inovação é fruto da criação, em que as áreas do conhecimento são tensionadas, não podemos definir a priori os espaços em que ela vai ocorrer, inclusive porque a inovação educacional é sempre contingente, e não 
universal. Ela poderá estar na universidade, mas poderá também estar na escola, conforme observamos nas experiências do Pibid. 0 que temos que fazer circular é outro entendimento de teoria e prática, tanto nas universidades quanto nas escolas, o que acabará tornando complexo o conceito de inovação.

Neste momento, acreditamos ser importante trazer alguns autores que têm sido referência nos estudos sobre inovação. Apoiamos nossos argumentos primeiramente em Cunha (2003, p. 150), que tem realizado importantes estudos sobre inovação no campo educacional, mais especificamente na universidade. A autora chama a atenção para o fato de que "as inovações que procuramos afirmar no campo acadêmico enfrentam toda a dificuldade decorrente da presença paradigmática dominante". Para Cunha,

As inovações que adivinhamos próximas se materializam pelo reconhecimento de formas alternativas de saberes e experiências, nas quais imbricam objetividade e subjetividade, senso comum e ciência, teoria e prática, cultura e natureza, anulando dicotomias e procurando gerar novos conhecimentos mediante novas práticas. Essas inovações, entendidas como ruptura paradigmática, exigem dos professores reconfiguração de saberes [...]. (Cunha, 2003, p. 150)

Ainda segundo a autora (2008, p. 22), para que ocorra inovação, é preciso que haja uma ruptura "que permita reconfigurar o conhecimento para além das regularidades propostas pela modernidade. Ela pressupõe, pois, uma ruptura paradigmática e não apenas a inclusão de novidades [...]".

Nesse sentido, buscamos trazer alguns pontos a que precisamos ficar atentos. Em especial, chamamos a atenção para a busca de novidades e de práticas ativas como sinônimos de avanço, inovação e atualidade, o que podemos identificar a partir das análises realizadas. Parece que a tradição perde lugar, porém, queremos ressaltar que não se trata de assumirmos mais definições e categorias classificatórias, mas de assumir práticas que tenham significado no contexto em que são utilizadas. Práticas que bebem na cultura, mas que buscam, no conhecimento sistematizado da área, o que há de melhor e mais atual e que o problematizam frente às diferenças culturais. Então, como defende Gallo ${ }^{8}$ (2012), a docência possui algo de transmissão (da tradição) e algo de inovação.

Inovação, palavra derivada do termo latino innovatio, refere-se a uma ideia, método ou objeto que é criado e que pouco se parece com padrões anteriores. Em tempos contemporâneos, a inovação tem estado intimamente ligada à economia e ao mercado. Falando de um lugar da economia, Freeman (1995) afirma que a inovação, ao aumentar a competitividade, é considerada fator fundamental para o crescimento econômico de um país.

Acreditando que a educação e a economia estão intimamente ligadas, nessa lógica de governo, foi possível perceber que o Pibid, ao atuar em consonância com

8. Depoimento constante no banco de dados da pesquisa. 
as necessidades do mercado, contribui para a formação continuada, melhora o desempenho dos professores, coopera com o aumento da atratividade da carreira docente e com a valorização das licenciaturas, torna os professores mais produtivos e suas práticas mais eficazes, em consonância com uma racionalidade neoliberal. Dessa forma, colabora também com a melhoria dos índices do ldeb e os resultados dos alunos brasileiros em avaliações internacionais de larga escala, como o Pisa.

A partir desses entendimentos, vamos buscar, em uma autora que vem produzindo significativas análises sobre a produtividade das relações que se estabelecem nessa nova fase do capitalismo contemporâneo, uma ligação com o que encontramos em nossa pesquisa. Ela diz:

A formação e inovação permanentes são partes indissociáveis de um novo estágio do capitalismo, qual seja o capitalismo do conhecimento, que tem no saber a sua principal força produtiva. Nesse cenário, não há mais o monopólio do capitalismo sobre os meios de extração e reprodução do saber operário, como ocorria no taylorismo e no velho management. As sociedades de controle, segundo Deleuze, seriam resultado de uma inovação tecnológica promovida por novas máquinas. A cada sociedade, diz o filósofo, corresponde um tipo de máquina. As da sociedade de controle seriam os computadores. Mas, como também nos informa Deleuze, não se deve vincular o nascimento das sociedades de controle ao resultado natural da inovação tecnológica, mas a uma profunda mutação do capitalismo que não apenas levou a essa busca por inovação, como também passou a requerer novas formas de agenciamento coletivo. (Fontanelle, 2012, p. 106)

Ao encaminhar-nos para a finalização deste texto, afinamo-nos com esse entendimento de Fontanelle, pois o imperativo da inovação não é um mandamento só da área da gestão ou da educação, mas envolve todos nós que vivemos nessa condição que muitos têm chamado de pós-moderna. É uma condição que nos interpela para que assumamos outras formas de análise e compreensão dos acontecimentos sociais, já que não é mais possível posicionar-se contra esses processos, como diz a autora referida anteriormente. Segundo ela, teríamos que inventar a potência da crítica com outros jogos descritivos.

\section{Considerações finais: um link para a continuidade da pesquisa}

Anunciamos o risco que corremos ao ousarmos empreender, no pequeno espaço deste texto, uma análise envolvendo tamanha complexidade. Convidamos os leitores a assumirem conosco o desafio de pensar sobre a formação docente e a constituição da docência no cenário contemporâneo, a partir da relação educação básica e universidade, em articulação com as teorizações foucaultianas.

Ao retomarmos a epígrafe que inicia esse texto, podemos dizer que as práticas do Pibid analisadas neste recorte de pesquisa nos mostra que o programa desenvolve as 
bases da formação de professores no acompanhamento, na formação-em-situação e integração na cultura profissional docente, mas que experiências de análise da prática, ao menos no material que olhamos, ainda é quase inexistente.

As discursividades sintetizadas pelas expressões mobilização, inovação, parceria e trabalho coletivo, podem estar anunciando uma estrita ligação com o que estamos argumentando nesse texto, uma racionalidade neoliberal em que a formação de professores é importante para agenciar e criar sujeitos empreendedores. Essas três expressões mostram um alinhamento com pedagogias psicológicas, que há muito tempo dominam a cena pedagógica. Talvez também nelas possamos encontrar discursos que se contrapõem a tudo que é passivo, estático, silencioso e se alinham ao discurso da inovação visibilizado no material e entendido pelos sujeitos do programa muito mais como novidades e como contrários à tradição.

A parceria e o trabalho coletivo, um grande desejo das teorizações críticas, aparecem agora como economia política e como desresponsabilização do Estado por ações que seriam de sua competência. Em síntese, a iniciação à docência a partir do material analisado coloca em funcionamento três tecnologias: a participação, a responsabilização dos sujeitos e a inovação.

Deixamos no final deste texto um link para a conexão com a continuidade da pesquisa. Esperamos que os esforços empreendidos ofereçam subsídios para a discussão sobre como o Pibid vem impactando os processos de formação inicial e de formação continuada na relação universidade e escola.

Queremos reafirmar nossa crença em programas como o Pibid. Nossa análise transita nesse espaço da crítica que se vê perturbada por discursos que se apresentam de tal forma positivados, que não conseguimos questionar nem mesmo sua condição de contingência, pois vêm atrelados a imperativos que fragilizam o pensamento radical ao naturalizar e incluir tudo e todos em processos que nos capturam como sendo "acima de qualquer suspeita" e, o mais grave, parecendo situar-se na mesma matriz de inteligibilidade daquelas práticas que defendemos, como o próprio Pibid.

É esse o nosso incômodo e o de muitos pesquisadores que já não conseguem mais acompanhar a proliferação intensa de sentidos que os discursos produzem sobre objetos, acontecimentos e sujeitos ao serem capturados e incorporados por esta fase contemporânea do capitalismo, que tem na cultura uma parceira produtiva (Fontanelle, 2012). Aquilo e aqueles que antes nos eram tão familiares, hoje, nessa bruma da ambiguidade discursiva, não conseguimos mais identificar: o que ou quem são, como vivem e o que almejam.

Parece que o mundo se tornou "totalmente igual", embora com a proliferação das diferenças exaltada. As ferramentas de pesquisa e da própria crítica precisam ser afiadas. Esse é o desafio que indicamos a nós mesmas e a quem nos lê. 


\section{Referências}

CASTRO, Edgardo. Vocabulário de Foucault - um percurso pelos seus temas, conceitos e autores. Tradução de Ingrid Muller Xavier; revisão técnica de Alfredo Veiga-Neto e Walter Omar Kohan. Belo Horizonte: Autêntica, 2009.

BUJES, Maria Isabel Edelweiss. Infância e maquinarias. Rio de Janeiro: DP\&A, 2002.

CUNHA, Maria Isabel da. Inovações pedagógicas: tempos de silêncios e possibilidades de produção. Revista Interface Comunicação, Saúde, Educação, v.7, n.13, agosto, 2003, p.149-58. Fonte: http://www.interface.org.br/revista13/debates1.pdf/10p

. Inovações pedagógicas: o desafio da reconfiguração de saberes na docência universitária. São Paulo: Cadernos Pedagogia Universitária, 2008.

FOUCAULT, Michel. Nascimento da biopolítica. In: Resumo dos Cursos do Collège de France (1970-1982). Rio de Janeiro: Jorge Zahar Ed, 1997.

. Diálogo sobre o poder. In: FOUCAULT, Michel. Ditos e Escritos IV: Estratégia, Poder-Saber. Rio de Janeiro: Forense Universitária, 2003. p. 355-386.

Microfísica do poder. $21^{\text {a }}$ ed. Rio de Janeiro: Graal, 2005.

O governo de si e dos outros: curso no Collège de France (1982/1983). São

Paulo: WMF Martins Fontes, 2010.

Do governo dos vivos: curso no Collège de France: excertos/ Michel Foucault (1979-1980). Trad. Nildo Avelino. São Paulo: Centro de Cultura Social. Rio de Janeiro: Achiamé, 2010a.

FONTENELLE, Isleide. Para uma crítica ao discurso da inovação: saber e controle no capitalismo do conhecimento. Revista de Administração de Empresas, São Paulo, Fundação Getúlio Vargas, v. 52, n. 1, p. 100-108, jan-fev 2012.

FREEMAN, Christopher. The National System of Innovation in Historical Perspective. Journal of Economics, Cambridge, Oxford Journals, n. 19 (1), 1995, p. 5-24.

MENEZES, Eliana. A maquinaria escolar na produção de subjetividades para uma sociedade inclusiva. 2011. 189 páginas. Tese (Doutorado em Educação). Programa de Pós-graduação em Educação, Unisinos.

NóVOA, António (2011). O Regresso dos Professores. Livro Digital. Disponível em: < http://pt.scribd.com/doc/68387246/0-regresso-dos-professores>.

REVEL, Judith. Nas origens do biopolítico: de Vigiar e Punir ao pensamento da atualidade. In: GONDRA, José; KOHAN, Walter (orgs). Foucault 80 anos. Belo Horizonte: Autêntica, 2006.

VEIGA-NETO, Alfredo. Educação e governamentalidade neoliberal: novos dispositivos, novas subjetividades. In: CASTELO BRANCO, Guilherme; PORTOCARRERO, Vera (org). Retratos de Foucault. Rio de Janeiro: Nau, 2000, p. 179-217.

Coisas de governo... In: RAGO, Margareth; ORLANDI, Luiz B. L. \& VEIGANETO, Alfredo (org). Imagens de Foucault e Deleuze: ressonâncias nietzchianas. Rio de Janeiro: DP\&A, 2002, p. 13-34.

Faces da diferença (entrevista). Ponto de Vista, Florianópolis, Universidade Federal de Santa Catarina, n. 5, 2003, p. 207- 216, 2003. Acesso em novembro de 2011. 
Disponível em: <www.perspectiva.ufsc.br/pontodevista_05/11_entrevista.pdf>. ; LOPES, Maura Corcini. Para pensar de outros modos a modernidade pedagógica. São Paulo: Vol. 12, n. 1, 2010. Revista digital - ETD. Faculdade de Educação da UNICAMP. Disponível em < http://www.fae.unicamp.br/etd/>.

Recebido em janeiro de 2013

Aprovado em maio de 2013

Elí Henn Fabris é doutora em Educação, professora do Programa de Pós-graduação em Educação da Universidade do Vale do Rio dos Sinos (Unisinos), e coordenadora do Grupo de Estudo e Pesquisa em Inclusão (GEPI). Email: fabris2000Quol.com.br

Sandra de Oliveira é mestre em Educação e doutoranda do Programa de Pósgraduação em Educação da Universidade do Vale do Rio dos Sinos - Unisinos. Email: sandradeoliveira.rságmail.com 